\title{
Sales Forecast of an Automobile Industry
}

\author{
Rashmi Sharma \\ ABES Engineering College Ghaziabad
}

\author{
Ashok K. Sinha \\ ABES Engineering College Ghaziabad
}

\begin{abstract}
Sales forecast plays a prominent role in business strategy for generating revenue. Sales forecast depends on some of the factors as the market demand, promotion strategy used, living standard of the people, inflation rate, consumables price, public image of the company, market share, quality of service and so on. In this paper sales forecast of Maruti Suzuki Ltd, an automobile industry in India is considered. The inflation rate, petrol price, previous month sale are found to be more prominent parameters influencing the sales forecast of cars in this company. The model is trained using Fuzzy Neural Back Propagation Algorithm. The result thus obtained is compared with other statistical technique like multiple regression technique. However the result obtained by proposed algorithm is found to be superior to the result obtained by multiple linear regression technique.
\end{abstract}

\section{General Terms}

Neural Networks, Fuzzy System, Decision Support System, Multiple Linear Regressions

\section{Keywords}

Sales Forecast, FBPN, Non-linear method, Automobile Industry

\section{INTRODUCTION}

The automotive sector is one of the core industries of the Indian economy. After allowing continuous economic liberalization in since 1991 the auto industry has witnessed a phenomenal growth in the last two decades. India has attracted many global automotive players in recent years. The industry has greatly benefitted from increase in the paying capacity of the consumers; this has led to an increase market demand.

For the sales forecasting to be accurate, managers need to consider all or some of the following factors: historical perspective, business competence, market position, generic economic conditions, price index, intra-company trends, product trends, sources and magnitude of product demand.

A sales forecast predicts the value of sales over a period of time. It becomes the basis of marketing mix and sales planning. Sales forecasting is crucial because without a proper sales forecast a company cannot program to attain the desired sales and marketing objectives. It is based on a number of assumptions regarding customer and competitor behavior as well as the market environment, and therefore, its reliability depends upon a number of uncertain parameters.

Management analyzes previous sales experience by product lines, territories, classes of customers, and other relevant details. Management needs to consider a time line long enough to detect trends and patterns in the growth and the decline of sales volume. The ability of a company to respond to the results of a sales forecast depends on its production capacity, marketing methods, financing, and leadership, and its ability to change each of these to maximize its profit potential. Sales forecasting also considers the competitive position of the company with respect to its market share; research and development; quality of service, pricing and financing policies; and public image. Forecasters also evaluate the quality and quantity of the customer base to determine brand loyalty, response to promotional efforts, economic viability, and credit worthiness. The condition of the overall economy is still a primary determinant of general sales volume. If the prices for products have changed over the years, changes in volume of sales may not correlate well with volume of units. At one point in time when demand is strong, a company raises its prices. At another time, a company may engage in discounting to draw down inventories. This process is similar to an inflation index, which provides constant prices. Forecasters study the underlying assumptions of trend variations to understand the important relationships in determining the volume of sales. By analyzing month-tomonth trends and seasonal variations over both the long and short terms, business owners and managers can adjust the sales forecast to anticipate variations that historically repeat themselves during budget periods. Forecasters also trend individual products, using indexes to adjust for seasonal fluctuations and price changes. Product trends are important for understanding the life cycle of a product. Consumer attitude and lifestyles anticipate product introductions and technological changes. Demand based on anticipation is becoming the dominant feature of the technological age. The rapid pace of technological development and new product introductions have shortened product life-cycles.

The most commonly used techniques for sales forecasting include statistically based techniques like time series, regression techniques and computational intelligence method like fuzzy systems, artificial neural networks and neuro-fuzzy systems $[9,10,11,12]$. Several forecasting techniques have been developed, each one with its particular advantages and disadvantages compared to other approaches.

Pei-Chann Chang, Yen-Wen Wang [1] proposed sales forecasting in PCB industry using Fuzzy Delphi and backpropagation model and demonstrated effectiveness of the fuzzy back propagation network (FBPN) that is superior to other traditional approaches. The input data is divided into three domains- Market demand domain, Macroeconomics domain and Industrial production domain.

Mirnaser Mirbagheri [2] recognized the effective variables which effect economic growth in Iran, and then applied appropriate means for modeling and forecasting the main macroeconomic variables.

Stefka Stoeva, Alexander Nikov [5] presented an extension of the standard backpropagation algorithm (SBP).In this research SBP and FBP are compared .Fuzzy back propagation algorithm shows considerably greater convergence rate compared to SBP algorithm without oscillations.

Gholamreza Jandaghi, Reza Tehrani, Davoud Hosseinpour, Rahmatollah Gholipour and Seyed Amir Shahidi Shadkam [6] proposed a model based on Fuzzy-neural networks for the prediction of stock price. The prediction was done by the two linear and nonlinear models for one ahead and multi ahead in stock price by using exogenous variable of stock market cash index, and the results show the preference of nonlinear neural- 
Fuzzy model to classic linear model and verify the capabilities of Fuzzy-neural networks in this prediction.

Yan Liu, Min Sun [7] proposed the use of fuzzy optimization BP neural network as a management tool for the maintenance of expressway pavement.

\section{METHODOLOGY}

1. The significant parameters of the model are identified

2. The proposed sales forecast model is represented by artificial neural network (ANN).

3. The ANN model is trained by past data on inputs and the outputs.

4. The model error is compared with the error obtained by multiple regression technique.

5. Using the converged values of interlayer coefficients sales forecast can be computed.

\subsection{Parameters of the Model}

It is important to examine some of the significant factors that affect the sale of goods.

1. Price of the Product- There is inverse relationship between price and the amount consumers are willing and able to buy is often referred to as the law of demansd.

2. The Consumer's Income -For most goods, there is a positive (direct) relationship between a consumer's income and the amount of the goods that one is willing and able to buy.

3. Consumer Awareness- The percentage of population or target market, who are aware of the existence of a given brand or company.

4. Inflation rate - The fall in the value of local currency in the global market.

5. Petrol/ Diesel Rate - The increasing rate of the crude oil in international market affects the petrol / diesel rates in India.

In the context of Maruti Suzuki India

1. Price of the product is not considered, as the company has good market value.

2. These days ample loan facilities are available so the consumer's income also does not directly affect the sale of the product.

3. Consumer's awareness is evident from the past sales of the product.

4. Inflation rate affects the sale as it directly affects the loan installments and the resale value of the product.

5. Diesel/Petrol is a consumable in the product and required on daily basis. So it affects monthly expenditure of the consumer.

The significantly affecting parameters considered in our model are:

1. Inflation Rate

2. Petrol/Diesel Price

3. Sale of the previous month

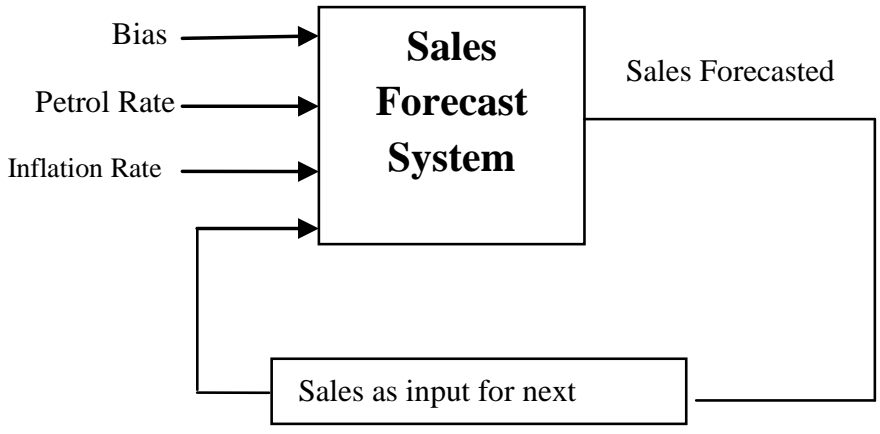

Figure 1: Sale Forecast System

\subsection{Neural Network Architecture}

The neural network model used in the study is the multilayer perceptron (MLP) also known as a supervised network. This network requires a desired output in order to learn, achieved by creating a model that correctly maps the input to the output using historical data so that the model can then be used to produce the output when the desired output is unknown. This uses three-layer architecture: input (known parameters), hidden layer, and output layer (known value)

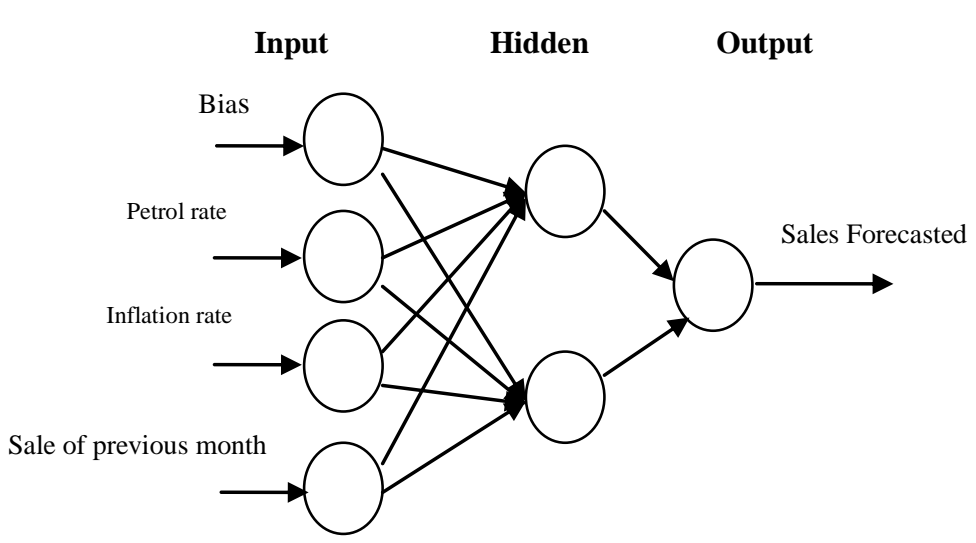

Figure 2: Neuro fuzzy Model for Sale Forecast System

\subsection{Model implementation in Neural Network}

A sample of data on Inflation rate, Petrol rate, actual sales of previous month are shown in the table I.

\section{Neural network parameters are:}

Number of patterns for training - 11

Nodes in input layer - 4 (Three parameters and one bias)

Hidden layer - 1

Nodes in hidden layer - 2

Nodes in output layer - 1

Weights between input layers and hidden layers - 8

Weights between hidden layers and output layer - 2

Learning rate $(\eta)-0.3$

Constant value $(\alpha)-0.5$

Number of iterations - 50

Software used - Program ( $m$ file) developed on MATLAB 7.0 
Table 1. Actual data considered for the system training ( Sales data For Year 2011)

\begin{tabular}{|c|l|l|l|l|l|}
\hline $\begin{array}{c}\text { S. } \\
\text { No. }\end{array}$ & Month & $\begin{array}{c}\text { Petrol } \\
\text { Price }\end{array}$ & $\begin{array}{c}\text { Inflati } \\
\text { on } \\
\text { Rate }\end{array}$ & $\begin{array}{c}\text { Previo } \\
\text { us } \\
\text { month }\end{array}$ & $\begin{array}{c}\text { Curr } \\
\text { ent } \\
\text { mont } \\
\text { h }\end{array}$ \\
\hline 1 & January & 58.37 & 9.47 & 66290 & 74355 \\
\hline 2 & Februray & 58.37 & 9.3 & 74355 & 74802 \\
\hline 3 & March & 58.37 & 8.82 & 74802 & 81375 \\
\hline 4 & April & 58.37 & 8.82 & 81375 & 59971 \\
\hline 5 & May & 63.37 & 9.41 & 59971 & 65237 \\
\hline 6 & June & 63.37 & 8.72 & 65237 & 54422 \\
\hline 7 & July & 63.7 & 8.62 & 54422 & 47127 \\
\hline 8 & August & 63.7 & 8.43 & 47127 & 53539 \\
\hline 9 & September & 66.84 & 8.99 & 53539 & 57049 \\
\hline 10 & October & 66.84 & 10.06 & 57049 & 35868 \\
\hline 11 & November & 66.42 & 9.39 & 35868 & 61080 \\
\hline
\end{tabular}

Mean Square Error (MSE) is calculated as follows:

$$
M S E=\frac{1}{n} \sum_{t=1}^{n}\left(D_{t}-F_{t}\right)^{2}
$$

Where

$D_{t}$ is predicted by the individual program for a pattern $t$

$F_{t}$ is the targeted value for a pattern $t$

$\mathrm{n}$ is the total number of pattern

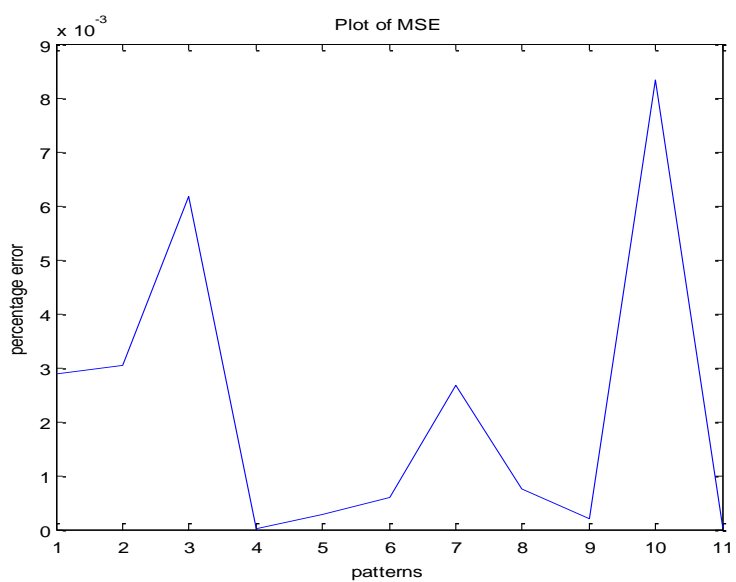

Figure 3: Graph plotting the patterns vs. \% error

\section{Mean Square Error $(\mathrm{MSE})=\mathbf{7 . 7 7 2 8 \mathrm { e } - 0 0 6}$}

In the first stage the model is trained with set of known input values of sale with random weights assigned. The error measures (actual value minus computed value) are distributed to the elements in the hidden layers using back propagation. Different weights connecting different elements in the network are corrected till the values converge within acceptable range.

\subsection{Model implementation in Multiple Linear Regressions}

The directly affecting parameters are the same:

1. Inflation Rate

2. Petrol/Diesel Price

3. Sale of the previous month.

The equations used are for $100 \%$ confidence

$[\mathrm{b}$, bint, $\mathrm{r}$, rint, stats $]=\operatorname{regress}(\mathrm{y}, \mathrm{X})$;

For $100 \%$ confidence level the residuals lies between +0.35 to $-0.35$

The equations used are for $50 \%$ confidence

$[\mathrm{b}$, bint, $\mathrm{r}$, rint, stats $]=\operatorname{regress}(\mathrm{y}, \mathrm{X}, 0.5)$;

For $50 \%$ confidence level the residuals lies between +0.2 to 0.2

Here $\mathrm{X}$ is calculated by

$\mathrm{X}=[\operatorname{ones}(\operatorname{size}(\mathrm{x} 1)) \mathrm{x} 1 \mathrm{x} 2 \mathrm{x} 3]$;

Where $\mathrm{X} 1$ is Inflation rate,

$\mathrm{X} 2$ is Petrol rate

$\mathrm{X} 3$ is Sales of previous month

Here $y$ is the actual sale of the month

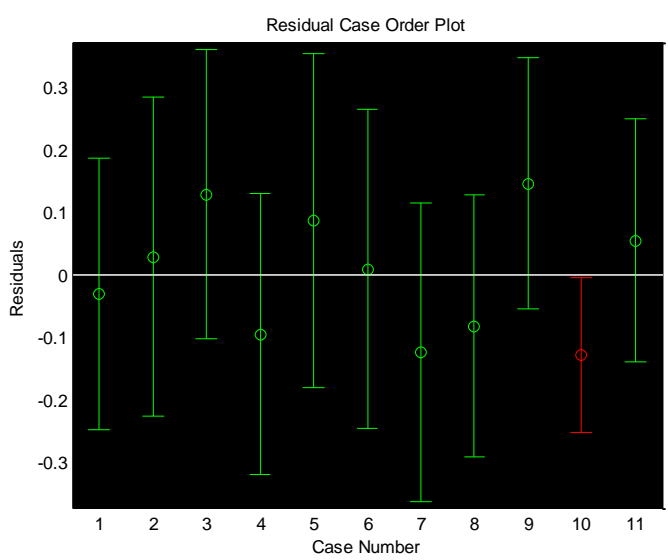

Figure 4: Residue case order plot (for $100 \%$ confidence level)

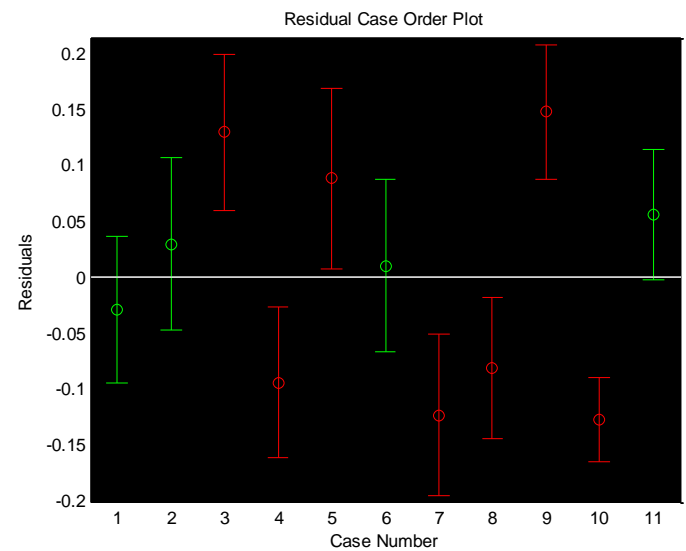

Figure 5: Residue case order plot (for $50 \%$ confidence level) 
Table 2. Comparison of Minimum and Maximum values of both models

\begin{tabular}{|c|c|c|c|c|}
\hline & $\begin{array}{l}\text { Maximum } \\
\text { Value }\end{array}$ & $\begin{array}{l}\text { Minimu } \\
\mathrm{m} \text { value }\end{array}$ & Range \\
\hline \multicolumn{2}{|c|}{$\begin{array}{l}\text { Neural Network } \\
\text { Model }\end{array}$} & $8.3 \times 10^{-3}$ & 0 & $8.3 \times 10^{-3}$ \\
\hline \multirow{2}{*}{$\begin{array}{l}\text { Multiple } \\
\text { Linear } \\
\text { Regressi } \\
\text { on } \\
\text { Model }\end{array}$} & $\begin{array}{c}100 \% \\
\text { confidenc } \\
\mathrm{e}\end{array}$ & 0.3611 & -0.3626 & 0.7237 \\
\hline & $\begin{array}{c}50 \% \\
\text { Confidenc } \\
\mathrm{e}\end{array}$ & 0.2079 & -0.1956 & 0.4035 \\
\hline
\end{tabular}

\section{CONCLUSION}

The present work has successfully implemented sales forecast model of an automobile industry using Fuzzy BPN algorithm. The result obtained by neural network is further compared with the result obtained by multiple linear regression analysis. The result obtained by multiple linear regressions have range of 0.7237 for $100 \%$ confidence and 0.4935 for $50 \%$ confidence. The result range obtained by proposed algorithm is of order $8.3 \times 10^{-3}$ and is found to be superior to the result obtained by multiple linear regressions. The error obtained by neuro-fuzzy BP architecture is 7.7728e-006.

\section{REFERENCES}

[1] Chang Pei-Chann, Wang Yen-Wen (2006). Fuzzy Delphi and back propagation model for sales forecasting in PCB industry Expert Systems with Applications 30 (2006) 715-726.

[2] Mirbagheri Mirnaser(2010). Fuzzy-logic and Neural network Fuzzy forecasting of Iran GDP growth. African Journal of Business Management Vol. 4(6), pp. 925-929.

[3] Escoda , A.Ortega, ASanz , A.Herms (1997) Demand Forecasting by neural fuzzy technique IEEE, FUZZ-
IEEE’97 page no.1381-1386Tavel, P. 2007 Modeling and Simulation Design. AK Peters Ltd.

[4] Jingtao Yao, Nicholas Teng, Hean-Lee Poh, Chew Lim Tan(1998) Forecasting and Analysis of Marketing Data Using Neural Networks Journal Of Information Science And Engineering 14, 843-862.

[5] Stoeva Stefka, Nikov Alexander(2000) .A fuzzy backpropagation algorithm. Fuzzy Sets and Systems 112 (2000) 27-39.

[6] Gholamreza Jandaghi, Reza Tehrani, Davoud Hosseinpour, Rahmatollah Gholipour and Seyed Amir Shahidi Shadkam ,Application of Fuzzy-neural networks in multi-ahead forecast of stock price African Journal of Business Management Vol. 4(6), pp. 903-914, June 2010

[7] Yan Liu, Min Sun Fuzzy Optimization BP Neural Network Model for Pavement Performance Assessment Proceedings of 2007 IEEE International Conference on Grey Systems and Intelligent Services, November 18-20, 2007, Nanjing, China.

[8] Jason E. Kutsurelis, Forecasting Financial Markets Using Neural Networks: An analysis of methods and accuracy, Thesis September 1998 , Naval Postgraduate School Monterey, California.

[9] Rajasekaran S,Vijayalakshmi G.A.,"Neural Networks,Fuzzy Logic and Genetic Algorithms",PHI, 2003.

[10] Little, John D. C., Decision Support Systems for Marketing Managers, Journal of Marketing (pre-1986); Summer 1979; 43, 000003; ABI/INFORM Global pg. 9.

[11] Horris C. bung, (1995) Neural Network in supply chain, Engineering Management-Conference, IEEE, pg 347352.

[12] A. Weigend and N. Gerschenfeld, Eds., Time Series Prediction: Forecasting the future and Understanding the past reading, MA: Addision-Wesley, 1994. 